\title{
Unilateral Pulmonary Agenesis in an Elderly Adult: A Case Report
}

\author{
${ }^{1}$ Wangkheimayum Asoka, ${ }^{2}$ Haorongbam Sunanda, ${ }^{3}$ Bhavya Shivalingaiah, \\ ${ }^{4}$ Namgay D Bhutia, ${ }^{4}$ Gerald Monsang, ${ }^{5}$ Tamar Paley. \\ Department of Respiratory Medicine, Regional Institute of Medical Sciences, Imphal.
}

\begin{abstract}
Pulmonary agenesis is a rare congenital anomaly, which is often associated with other systemic anomalies. Clinical presentation varies depending on the other systemic anomalies and complications associated with it. Although, it is usually diagnosed in a very early age, some cases go unnoticed up to adulthood. In this article, we present a case of an elderly woman who presented with fever and vague abdominal symptoms and was later diagnosed as a case of unilateral pulmonary agenesis.
\end{abstract}

Key Words: congenital anomalies, pulmonary agenesis, systemic anomalies

\section{Introduction}

Congenital pulmonary anomalies are seldom reported. Absence of the lungs results from the failure of the respiratory bud to develop. Unilateral agenesis is more common than bilateral but both conditions are rare. [1] Pulmonary agenesis differs from aplasia by the absence of a bronchial stump or carina that is seen in aplasia.[2]In the great majority of the cases, the diagnosis is usually made at or soon after birth and it can be associated with multiple anomalies. However, extremely rare asymptomatic cases may go unnoticed until adulthood.[3] Here by, we present a case of an elderly woman with unilateral pulmonary agenesis.

\section{Case Report}

A $60 \mathrm{y}$ old female housewife attended our emergency department with complaints of fever, pain abdomen, nausea and burning micturation for a duration of 6 days. She also complained of intermittent nonprogressive shortness of breath present only on exertion. There was no significant history of childhood illness or features suggestive of recurrent respiratory tract infection. No past significant medical or surgical history. On examination, vitals were stable with $\mathrm{SpO}_{2} 95 \%$ in room air. Examination of Respiratory system revealed volume loss on the left side with scoliosis, rib crowding and mediastenal shift. Breath sounds were absent on left side except on inter scapular area. Apical impulse was noted in the $5^{\text {th }}$ intercostal space lateral to mid clavicular line. On the right side, signs of hyperinflation were present. Per abdomen examinations were within normal limits. Routine blood tests were normal except for the mild increase in TLC $\left(13,300 / \mathrm{mm}^{3}\right)$ and ESR of $110 \mathrm{~mm}$ in $1^{\text {st }}$ hour. Urine examination revealed plenty of pus cells. Culture and sensitivity yielded E coli with significant colony count, sensitive to ceftrioxone. Chest $\mathrm{X}$ ray revealed signs of collapse with left complete opacification, ipsilateral tracheal and mediastenal shift, crowding of ribs and the diaphragm could not be made out. Hyperinflation of right lung with herniation towards left was noted. Multi Detector CECT thorax revealed complete absence of lung tissue and the main brochus on the left side with gross ipsilateral mediastinal shift(fig. 1). The right lung was seen herniating to the opposite side due to compensatory hypertrophy, with the heart occupying left posterior hemithorax(fig. 2) . Bone window showed semisegmented hemivertebra at D6/D7 with resultant scoliosis to the right and absent left $7^{\text {th }}$ rib (fig. 3). The pulmonary CT angiography confirmed absence of the left pulmonary artery and veins (fig. 4). The left brachiocephalic vein was seen separately draining into the right atrium in close proximity to the posterior thoracic wall (left superior venacava) (fig. 5). Fiberoptic bronchoscopic examination revealed that trachea was directly leading to right main stem bronchus and the right bronchial tree was within normal limits. Echocadiography and USG abdomen were within normal limits. The case was diagnosed as unilateral left sided pulmonary agenesis with associated congenital anomalies, bilateral superior venacava and semisegmented hemivertebra with urinary tract infection. Patient was treated conservatively for urinary tract infection. 


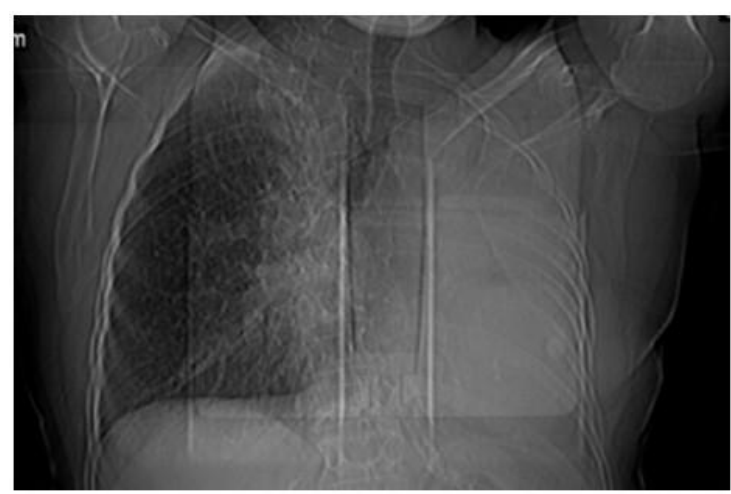

Figure 1: CT surview image showing abnormal opacification of the left hemithorax, features of volume loss in the left side with marked mediastinal shift
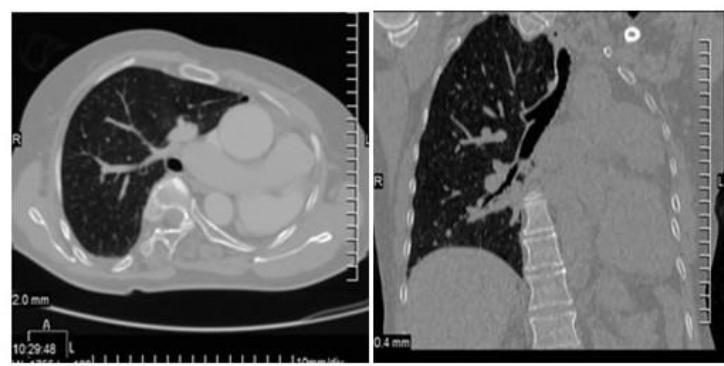

Figure 2: Axial \& coronal CECT image in lung widow showing absent left lung, main bronchus parenchyma and marked meadiastinal shift

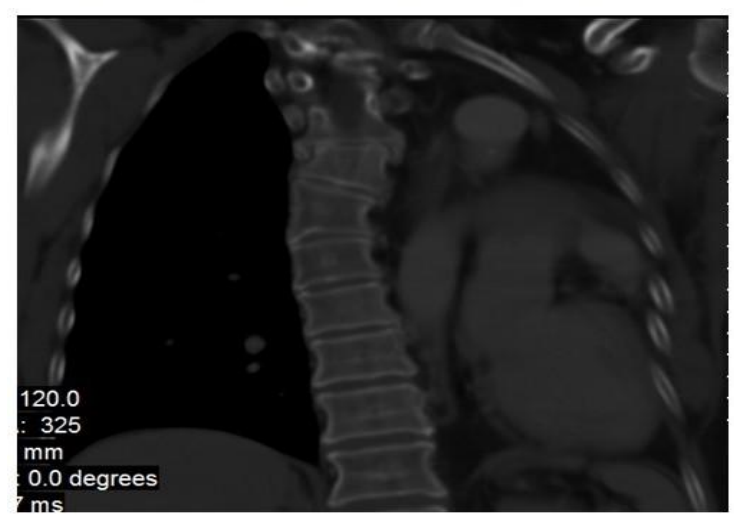

Figure 3: CECT Coronal bone window showing semisegmented hemivertebra at D6/D7

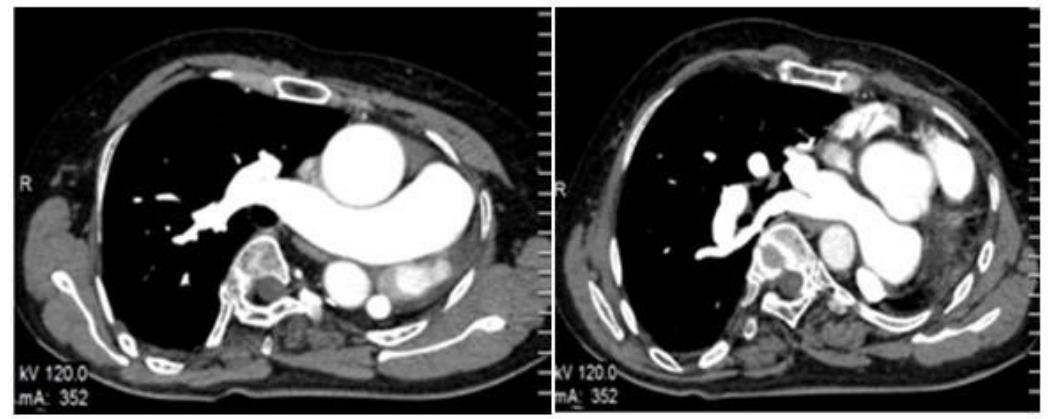

Figure 4: CT pulmonary angiography axial images showing absent left pulmonary artery and veins 

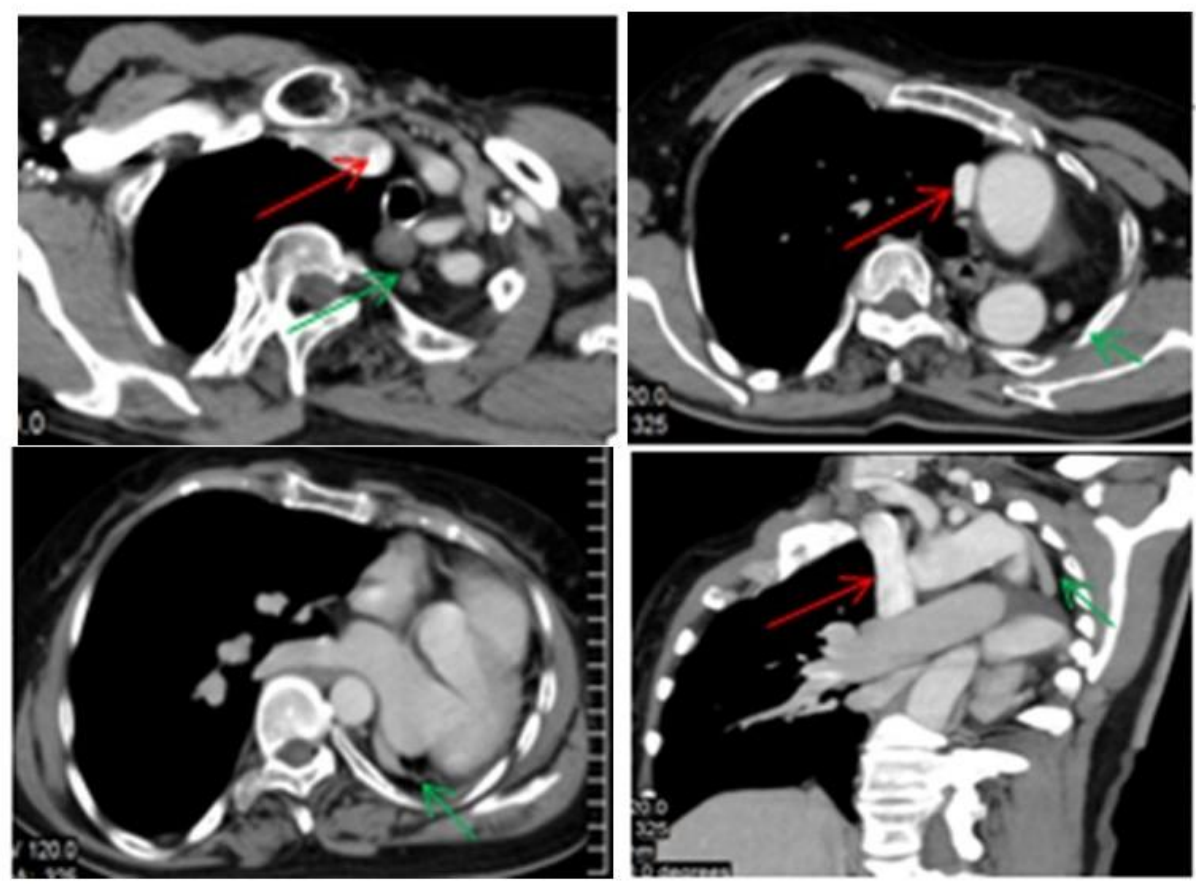

Figure 5: Axial \& MPR images showing origin \& course of bilateral brachiocepahlic veins (Bilateral Superior Venacava). Red arrow: right brachiocephalic vein; Green arrow: left brachiocephalic vein

MPR: Multi Planar Reconstruction

\section{Discussion}

Lung agenesis is a rare developmental anomaly and prenatal diagnosis is difficult during routine screening.[4] The estimated incidence is 1 per 10000-15000 autopsies.[5] Agenesis affects both lungs with equal frequency, with a slight female preponderance of 1.3:1. Long term survival with unilateral lung agenesis is possible in the absence of associated severe anomalies. However, the condition is frequently associated with other congenital abnormalities particularly esophageal atresia and the VACTERL syndrome (vertebral, anal, cardiac, tracheoesophageal, renal and radial and limb anomalies).[6]

Several authors have categorized their cases according to the classification of Boyden in 1955. In group 1 or pulmonary agenesis; the entire lung, bronchus and its pulmonary vessels are absent. In group 2 or pulmonary aplasia, the lung and pulmonary artery are absent, but there is a rudimentary bronchus coming off the trachea. In group 3 or pulmonary hypoplasia, there is hypoplastic bronchus with hypoplastic lung parenchyma.[7]Functionally, unilateral lung agenesis and lung aplasia are similar. Pathologically sole lung is larger than normal in pulmonary agenesis, and this enlargement is true hypertrophy and not emphysema.[8]

The tissues forming the lungs arise from the anterior endodermal cells that generate the ventral foregut. Targeted deletion arrests development of an identifiable lung. These includes homozygous null mutations of THYROID TRANSCRIPTION FACTOR-1, deficiency of RETINOIC ACID, CRE recombinase-mediated deletion of FIBROBLAST GROWTH FACTORS and RECEPTORS.[9]

The history may include dyspnoea, harsh breathing, repeated respiratory tract infection and respiratory distress with cyanosis on exertion. Patients presenting late usually have readily detectable flattening and reduced movement of the chest wall on the affected side, with reduced air entry on auscultation. Breath sounds from the herniated, hypertrophied lungs may be heard on the side of agenesis except in the axilla and base Chest wall deformity can be quite pronounced, with an associated secondary scoliosis.[8] As might be expected, chest radiographs in patients with unilateral absence of a lung show loss of aeration and marked volume loss on the affected side. Volume loss is shown as elevation of the ipsilateral hemidiaphragm, shift of the mediastinum toward the abnormal side, and anterior herniation of the contralateral lung. There is usually characteristic wedge shaped opacity in the inferior and lateral aspect of the affected hemithorax. This opacity is due to herniation of heart and mediastinum into the lower thorax and proliferation of fat to partially compensate for the absence of lung tissue. The obvious differential diagnoses are acquired total lung collapse or prior pneumonectomy.[10]

CT may be required to establish the degree of underdevelopment or to differentiate agenesis from other conditions that may mimic it radiographically.[11] Pulmonary angiography shows absence of ipsilateral pulmonary artery. Bronchoscopy demonstrates underdeveloped bronchus. Other investigations e.g.

DOI: $10.9790 / 0853-131271922 \quad$ www.iosrjournals.org $\quad 21 \mid$ Page


echocardiogram, ultrasound abdomen etc are required depending upon the presence of associated congenital abnormality.[12]

No treatment is required in asymptomatic cases. Management is mainly supportive, correcting associated malformations, prevention and treatment of repeated respiratory tract infections.[13] Prognosis depends on two factors. Firstly, the severity of associated congenital anomalies and secondly, involvement of the normal lung in any disease process. If patient survives the first five years without major infection, an almost normal life span can be expected. [14]

\section{References}

[1]. K.L. Moore, The developing human, clinically oriented embryology $8_{\text {th }}$ ed (Philadelphia;WB Saunders Company,2008)208

[2]. J.D. Finder JD. Congenital disorders of the lung R.M. Kliegman, B.F. Stanton, J.W. St. Geme, N.F. Schor, R.E. Behrman. Nelson textbook of paediatrics.19 th $_{\text {ed(Philadelphia:WB Saunders Company,2012) } 1463 .}$

[3]. H.P. Gunbey, W. Gunbey, A.T. Sayil , T. Bulut, Unilateral pulmonary agenesis in adulthood,Journal of Clinical and Diagnostic Research,20/6/2014,8(6)RD01-02.

[4]. Y. Zhang, M. Fan, W. Ren, L.M. Xie, C. Ding, W.Sun, et al. Prenatal diagnosis of fetal unilateral lung agenesis complicated with cardiac malposition. Bio Med Central.26/3/2013,13(79),1471-2393

[5]. M.C. Malcon, C.M. Malcon, M.N. Cavada, P.E. Caruso, L.F. Real. Uilateral pulmonary agenesis. Jornal Brasileiro de Pneumolgia 2012,38:526-529.

[6]. B.S. Clements. Congenital malformations of lungs and airways.in. L.M. Taussig , L.I. Landau(Ed.), Paediatric respiratory medicine,2 ( Philadelphia :lauraDe Young, 2008)1108-10

[7]. S. Albay ,F. Cankal , S. Tunali , H. Ozan ,Unilateral pulmonary hypoplasis, International Journal of Anatomic Variation, 13/10/2008,1:23-25

[8]. T.M.Krummel, Congenital malformations of the lower respiratory tract. E.L.Kendig(Ed.), Kendig's Disorders of The Respiratory Tract in Children. 6( Philadelphia: WB Saunders Company, 1998) 307-8.

[9]. J.M. Shannon, J.M. Greenberg, Lung growth and development., R.J. Mason, V.C. Broaddus, T.R. Martin, T.E. King, D.E. Schraufnagel,J.F.Murray,et al,Murray \& Nadel's Textbook of Respiratory Medicine,4(1) (Philadelphia: WB Saunders Company,2005)29-34.

[10]. D.M. Hansel , D.A. Lynch, H.P. McAdams, A.A.Bankier, Imaging of diseases of the chest.5(Mosby,Philadelphia,2010)1073.

[11]. R.S.Fraser, N.L. Muller, N.Colman, P.D. Pare, Diagnosis of diseases of chest 4 (1)( Philadelphia: WB Saunders Company, 1999) 598-601.

[12]. M.L.Gupta, S.R. Sharma, S. Singh, Congenital anomalies of the respiratory system, Behera D(Ed.), NCCP text book of respiratory medicine( NewDelhi: Jaypee brothers medical publishers, 2011) 870

[13]. P.P.Roy, S. Datta, A. Sarkar, A. Das, S. Das, Unilateral pulmonary agenesis presenting in adulthood, Journal of Respiratory Medicine Case reports,25/05/2011,81-83

[14]. P.Shrestha ,P. Poudel , P.L. Shah , Unilateral Pulmonary Aplasia: A Case Report, Journal of Nepal paediatric Society,Aug,2010:30(2)116-18 